\title{
Occupancy patterns and niche partitioning within a diverse carnivore community exposed to anthropogenic pressures
}

\section{Authors: Paul Schuette, Aaron P. Wagner, Meredith E. Wagner, \& Scott Creel}

NOTICE: this is the author's version of a work that was accepted for publication in Biological Conservation. Changes resulting from the publishing process, such as peer review, editing, corrections, structural formatting, and other quality control mechanisms may not be reflected in this document. Changes may have been made to this work since it was submitted for publication. A definitive version was subsequently published in Biological Conservation, [VOL\# 158, (February 2013)] DOI\# 10.1016/j.biocon.2012.08.008

Schuette P, Wagner A, Wagner M \& Creel S 2013. Occupancy patterns and niche partitioning within a diverse carnivore community exposed to anthropogenic pressures.

Biological Conservation 158:301-312.

Made available through Montana State University's ScholarWorks scholarworks. montana.edu 


\title{
Occupancy patterns and niche partitioning within a diverse carnivore community exposed to anthropogenic pressures
}

\author{
Paul Schuette ${ }^{\mathrm{a}, *}$, Aaron P. Wagner ${ }^{\mathrm{b}}$, Meredith E. Wagner ${ }^{\mathrm{c}}$, Scott Creel $^{\mathrm{a}}$ \\ ${ }^{a}$ Department of Ecology, Montana State University, Bozeman, MT 59717, USA \\ b BEACON Center for the Study of Evolution in Action, Michigan State University, East Lansing, MI 48824, USA \\ ${ }^{\mathrm{C}}$ School of Natural Resources and Environment, University of Florida, Gainesville, FL 32611, USA
}

\begin{abstract}
Although carnivores are in global decline, diverse carnivore communities are common in sub-Saharan Africa, where more than 20 species may co-occur. Though intraguild competition and predation can limit the set of species that coexist, most carnivores have traits that decrease the impacts of interspecific competition on fitness, a pattern that promotes coexistence. An increasing human population and demand for natural resources (e.g. farming) has fragmented landscapes, reduced available prey, and elevated rates of conflict. These anthropogenic pressures tend to eliminate large carnivores first, which can have cascading effects on ecosystem function (e.g. mesopredator release). Anthropogenic pressures might also affect mesocarnivores directly, but this hypothesis has received little research attention to date. Here, we used camera surveys to describe spatial and temporal patterns of carnivore occupancy in a mixed-use landscape in Kenya. This landscape included a community conservation area and seasonally occupied human settlement and livestock grazing areas. We detected 21 carnivore species and examined occupancy patterns for the 12 most frequently detected. Differences among species in responses to environmental conditions supported a hypothesis of spatial niche partitioning. Differences in the temporal activity patterns of the apex predators and mesocarnivores supported a hypothesis of temporal niche partitioning. Human land use altered occupancy patterns in 10 of 12 species. Apex predator occupancies were lower in more anthropogenically disturbed areas, but mesocarnivore occupancies were not inversely related to apex predators, contrary to the mesopredator release hypothesis. Our results suggest that a diverse carnivore community persists in this mixed use landscape because of seasonal variation in human land use.
\end{abstract}

\section{Introduction}

There has been substantial research on the influence of bottomup processes on carnivore populations (Creel et al., 2001), and this work clearly establishes the importance of habitat loss and prey depletion for carnivore conservation. However, the top-down process of intraguild competition and predation also influences carnivores' abilities to carve out ecological niches, which can affect distributions and abundances (Caro and Stoner, 2003; Creel et al., 2001; Palomares and Caro, 1999; Ritchie and Johnson, 2009). Several aspects of carnivore ecology probably strengthen the effects of interspecific competition in this guild. Most obviously, carnivores are morphologically and behaviorally adapted to killing, which can increase the likelihood that interference competition leads to intraguild predation (even though the killed competitor is frequently not consumed) or displacement from preferred habitats.
Additionally, the energetic costs of active hunting are high in comparison to most other foraging strategies (Creel and Creel, 1995; Gorman et al., 1998), and this strengthens selection in favor of kleptoparasitism from sympatric species even when live prey are abundant. For example, competitively dominant spotted hyenas (Crocuta crocuta) sometimes follow hunting groups of African wild dogs (Lycaon pictus), a subordinate competitor, to outnumber and steal their kills. (Creel and Creel, 1996; Estes and Goddard, 1967; Fanshawe and Fitzgibbon, 1993; Malcolm and Marten, 1982). Thus, interactions within a carnivore community can decrease a species' fitness (Creel and Creel, 1996; Gorman et al., 1998; Linnell and Strand, 2000) and increase the probability of a species' local or global extinction (Polis et al., 1989).

To offset the costs of interspecific competition, natural selection favors adaptations of morphology, life history, and behavior that limit the negative effects of competition on fitness (Creel et al., 2001; Hardin, 1960; Pfennig and Pfennig, 2005), and thus promote coexistence. Such niche partitioning is apparent in most carnivore guilds, where numerous physical traits (e.g. body size, stature, dentition, specialized sensory systems) and behavioral/ecological 
traits (e.g. solitary vs social, habitat and dietary preferences) have allowed competing species to coexist by partitioning resources (Fedriani et al., 2000; Karanth and Sunquist, 1995; Kitchen et al., 1999; Mills et al., 1984; Owen-Smith and Mills, 2008; Sinclair et al., 2003). Though the causal mechanism driving the evolution of physical attributes and behavioral strategies is often uncertain (e.g. sociality, (Nudds, 1978; Waser, 1981)), differences among species in derived characteristics promote coexistence, and many of the differences within carnivore communities are probably directly linked to competition. For example, attributes of skull morphology and dentition are uniformly distributed within guilds, as expected under the hypothesis that competition drives niche partitioning (Dayan et al., 1992). Active spatial and temporal avoidance at broad (geographic) scales and fine (habitat) scales can reduce the frequency of potentially costly encounters between a subordinate and dominant competitor (Creel et al., 2001; Durant, 1998; Fedriani et al., 2000; Hayward and Slotow, 2009; Linnell and Strand, 2000; Mills and Biggs, 1993; Neale and Sacks, 2001). These avoidance behaviors have been well-documented in the African wild dog and cheetah (Acinonyx jubatus), which avoid areas of high prey density because the competitively superior lion (Panthera leo) and spotted hyena prefer these areas (Durant, 1998; Creel and Creel, 2002).

Carnivores evolved their adaptations to interactions with guild members within large, heterogeneous ecosystems (Creel et al., 2001). However, an increasing human population and concomitant demand for land and natural resource extraction have fragmented landscapes, reduced available forage and prey items for carnivores, and increased the interface between people and carnivores (Woodroffe and Ginsberg, 1998; Woodroffe, 2000). Patterns of human land use change coupled with a decreased tolerance of conflict-prone species pose a threat to carnivore community structure and dynamics. In particular, large and competitively dominant species that pose a threat to human livelihoods have experienced drastic population reductions and shrinking distributions (Ray et al., 2005; Woodroffe and Ginsberg, 1998; Woodroffe, 2000). For instance, the African lion population in Kenya has declined from approximately 2750 individuals to 2000 in 10 years, a decline of nearly 30\% (Kenya's National Large Carnivore Task Force, 2008). Data on direct anthropogenic pressures on many smaller, cooccurring carnivores are sparse and the impacts are not as well understood (Martinoli et al., 2006; Pettorelli et al., 2010; Schipper et al., 2008). Nevertheless, fragmentation of carnivore communities and reductions in species richness have been described in disturbed areas (Dalerum et al., 2009). In most of the world, radical changes in the relative frequency of carnivore species have likely altered community function. For example, declines of a dominant species may prove advantageous to a subordinate species via numerical 'release' (i.e. mesopredator release), triggering cascading ecological effects (Crooks and Soulé, 1999; Ritchie and Johnson, 2009).

Alternatively, variation in human land use may help sustain native species richness in some taxa. For example, Gardner et al. (2007) showed that species richness in small mammals, amphibians, birds, butterflies, and trees did not change, but the composition of species did change across a gradient of land uses from strictly protected parks to areas of high human activity. Thus, heterogeneity in local land uses may protect or promote biological diversity at the regional scale, by creating areas with complimentary sets of species. This hypothesis is largely untested for carnivore communities. For example, in Serengeti National Park, lion and spotted hyena densities have increased in recent decades, resulting in reductions in the African wild dog and cheetah populations inside the park (Hanby and Bygott, 1995). Outside the park however, densities of lions and spotted hyenas have been reduced by trophy hunting (Packer et al., 2011) and human persecution, respectively, allowing African wild dogs and cheetahs to persist (Creel et al., 2001). In addition to numerical changes, human land use may also induce behavioral adjustments. For example, heavily persecuted species, such as the spotted hyena, can become more secretive or nocturnal in heavily human-modified landscapes (Boydston et al., 2003). Such behavioral changes in a dominant species may initiate a 'behavioral release' in subordinate competitors via broadening of temporal niches. Thus, while habitat loss, prey depletion, and overharvest make strictly protected areas of great importance for large carnivores (Cooley et al., 2009; Creel and Rotella, 2010; Packer et al., 2009; Robinson et al., 2008), these results suggest that richer and more diverse carnivore communities might be maintained in landscapes incorporating a mix of protected and human land uses, particularly when a community includes subordinate species excluded from fully protected areas by dominant species (Creel et al., 2001; Noss et al., 1996). Independent of this hypothesis, conservation and management requires an understanding of the dynamics of carnivore communities outside of fully-protected national parks, and such dynamics have been little-studied in Africa.

We used camera trapping and dynamic occupancy modeling (Fiske and Chandler, 2011; MacKenzie, 2003; MacKenzie et al., 2006) to examine the distribution of a diverse carnivore guild across a multiple human use landscape in Kenya's southern Rift Valley. This landscape is occupied by pastoralist Maasai people, and includes a community-run conservation area (CCA), seasonal livestock grazing grounds, and areas of permanent human settlement and use. This study was motivated by a lack of quantitative data on African carnivore communities across a range of human land uses. In addition, though the predominant form of land use in the southern Rift Valley is the rearing of livestock across an unfenced rangeland, many other East African rangelands are being subdivided and converted to farmland (Homewood et al., 2009). This regional trend could present a challenge to land use policy, wildlife management, and conservation strategies in the southern Rift Valley.

Our primary objectives were to quantify species richness, evaluate the impacts of environmental features and anthropogenic pressures on species occupancy patterns, and test for spatial and temporal niche partitioning among species across this multiple human land use landscape. Specifically, we tested the following hypotheses: (1) the combination of environmental conditions affecting occupancies will be unique for each species, creating a pattern of spatial niche partitioning within the local carnivore community, (2) small and medium-sized species occupancies will be higher in areas where large carnivore occupancies are low due to mesopredator release, (3) where large carnivore occupancies are high, temporal activity patterns of small and medium-sized species will be driven by temporal avoidance of lions and spotted hyenas, creating a pattern of temporal niche partitioning (Mills and Biggs, 1993), and (4) occupancies of conflict-prone species that directly threaten livestock (lions, spotted hyenas) will be more directly influenced by anthropogenic pressures than smaller, non-conflict species.

\section{Materials and methods}

\subsection{Study area}

This study was conducted in the southern Rift Valley of Kenya on the Olkiramatian and Shompole Maasai Group Ranches (GRs) $\left(\sim 1000 \mathrm{~km}^{2}\right)$. The full study area supports a low-density human population of Maasai pastoralists $\left(\sim 10\right.$ people $\left./ \mathrm{km}^{2}\right)$ and their livestock, which occur at moderate to high densities (sheep/goats: $59.1 \pm 17.0$ individuals $/ \mathrm{km}^{2}$, cattle: $15.8 \pm 5.7$ individuals $/ \mathrm{km}^{2}$ ) (Schuette, 2012). Despite increasing land subdivision and farming on surrounding rangelands (Homewood et al., 2009), the Olkiramatian and Shompole Maasai community continue to practice a semi-nomadic lifestyle, which is based on seasonal movements with their livestock to access grazing areas. This land use system 
provides a situation in which people and abundant livestock are distributed unequally across the landscape, with location and intensity of use changing seasonally (Schuette, 2012). The native large herbivore community is largely intact (all species except black rhinoceros) and abundant (Schuette, 2012). Though no prior data exist on the composition of the local carnivore community, African savannah ecosystems such as the one found in Olkiramatian and Shompole, are capable of supporting a diverse carnivore community composed of $>20$ native species (Caro and Stoner, 2003). Moderate levels of human-carnivore conflict occurred locally during our study. Spotted hyena were responsible for most reported conflicts (54\% of incidents), followed by leopard (28\%), lion (10\%), cheetah (4\%), and African wild dog (4\%) (Schuette et al., in press). Despite this, the practice of retaliatory spearing and poisoning of carcasses, which have been widespread across East Africa (Hazzah et al., 2009; Kissui, 2008; Virani et al., 2011), have been uncommon locally for at least the past decade (Kenya Wildlife Service, unpublished data).

We used a systematically-sampled grid of motion sensitive cameras to monitor the carnivore community throughout the study area. This area is open and unfenced in all directions, although the Rift Valley wall forms a geographic barrier to the west. Olkiramatian and Shompole GRs are situated $>100 \mathrm{~km}$ from any other government-protected area. The area receives low annual rainfall (400-600 mm/year) that falls almost exclusively during the long (March-May) and short (November-December) rainy seasons (Warinda, 2001), although the region received below average rainfall during 2009 (327 mm). The permanent Ewaso Nyiro River, flowing into the Shompole swamp, bisects the study area which provides a foraging refuge for livestock and wildlife during extended dry seasons.

Olkiramatian and Shompole GRs are partitioned into four land uses, with two primary land uses east and two land uses west of the Ewaso Nyiro River (Fig. 1). Moving from west (adjacent to Rift Valley wall) to east, the four land uses are as follows: (1) CCA (W of river): conservation area with no settlement and livestock only during severe drought and only during daylight. (2) Buffer (W of river): area adjacent to and between the CCA and the river, settled and grazed temporarily during dry seasons ( September-March). (3) Grazing zone (E of river): wet season grazing area ( $\sim$ MarchSeptember) with no human settlements. (4) Permanent settlement ( $E$ of river): area containing semi-permanent homes and also used as a wet season grazing area. Areas east of the river contain more people and livestock year-round, with the Permanent settlement area having the highest year-round human activity, including two small (<250 people) permanent villages (Fig. 2). In addition, the Permanent settlement area broadly appeared more arid, rocky, and has a different vegetation community than the other three land uses. We controlled for this difference in our analyses by incorporating site-level habitat and soil covariates (see below).

\subsection{Sampling design}

We used motion sensitive cameras with infrared flash (Moultrie Game Spy digital camera, 6.0 megapixel) to monitor carnivore activities and dynamics. We divided the landscape into 57 $\left(4 \mathrm{~km}^{2}\right)$ grids, each composed of $4\left(1 \mathrm{~km}^{2}\right)$ sub-locations (228 total), positioned across the four land uses $(C C A=40$, Buffer $=36$, Grazing zone $=57$, Permanent settlement $=95)$ in a regular manner that was logistically feasible (Fig. 1). We monitored wildlife over 28 consecutive months (April 2008-July 2010) by surveying one sublocation in each of the 57 grids for 3 nights and 4 days (consecutive) per month. We cycled sampling systematically across the four sub-locations within each grid cell over 4 month periods (e.g. NE sub-location in each grid in November 2009, SE in December 2009, SW in January 2010 and NW in February 2010.). This survey

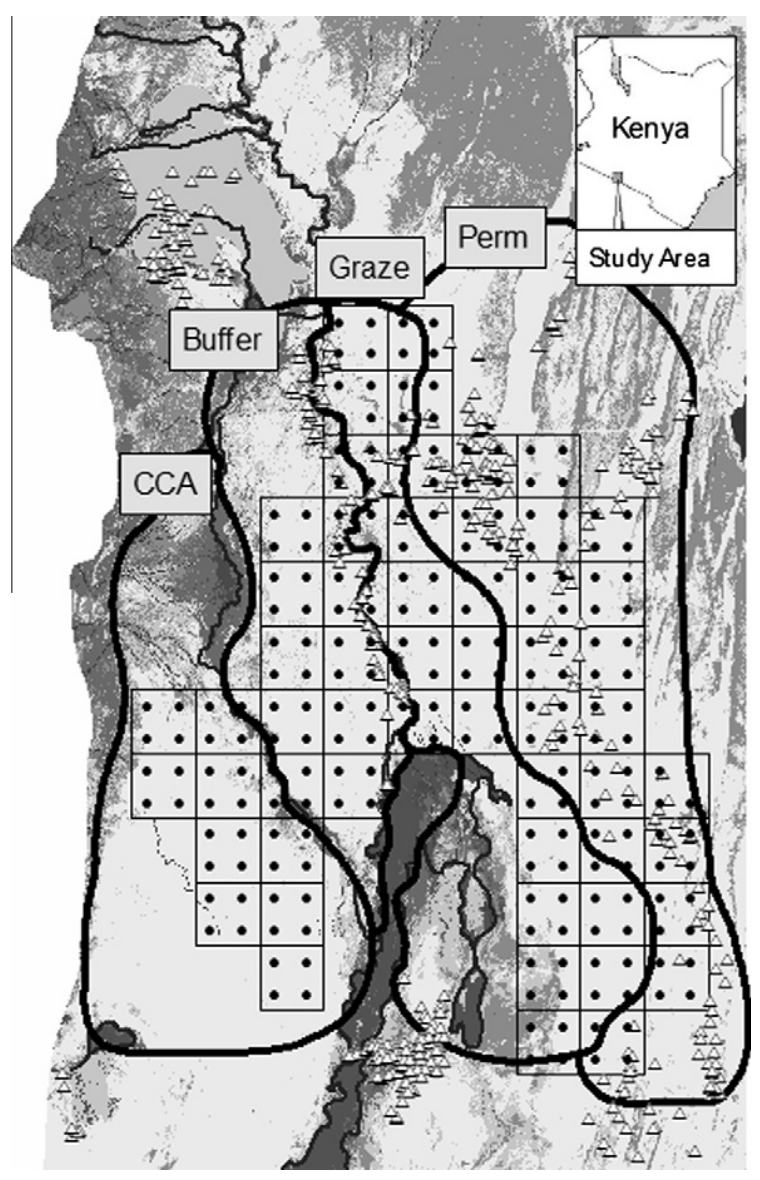

Fig. 1. Map of study area. Four different land uses are outlined: CCA (conservation area and drought refuge), Buffer (dry season settlements and grazing), Graze (wet season grazing with no settlements), Perm (Permanent settlements and grazing). Cameras were deployed at four sub-locations (dark circles) within 57 grids. Human settlements (triangles) mark all possible permanent and seasonal settlements, only a portion were active each season. A permanent river bisects the Buffer and Grazing areas and a seasonal stream roughly separates the CCA and Buffer. Gray regions to the west represent dense bush and woodland, gray regions to the east represent rocky terrain. The dark gray (bottom center) represents Shompole swamp.

design required 4 months to sample all 228 sub-locations. We consider each 4-month cycle of the 228 sub-locations as our primary sampling period ( 28 months $=7$ cycles). We further subdivided each sub-location survey into 7 secondary day and nighttime sampling occasions [ 3 at night (6:01 pm-6:00 am) and 4 during the day (6:01 am-6:00 pm)]. Implemented perfectly, our sampling design would have yielded 49 sampling occasions at each of the 228 sublocations, totaling 11172 sampling occasions. In practice, we sampled 9701 occasions.

At each sub-location, two cameras were placed at right angles to each other and at $4 \mathrm{~m}$ from a baited post $1 \mathrm{~m}$ in height. Each day we applied three commercially available hunting lures (Hawbakers Wildcat Lure No. 2, Carman's Triple X, and mountain lion urine), milk powder, and decomposed catfish to a pipe cleaner that we wrapped around the bait post. We set cameras $20-30 \mathrm{~cm}$ off of the ground, focused on the bait post. We set one camera to record three still images when triggered (at intervals of $15 \mathrm{~s}$ ), and the other to record a 5-s video followed by one still image. To avoid pseudoreplication, we recorded detection/non-detections of each carnivore species using a conservative strategy whereby multiple still images or videos of a species (or a group of that species) within a sampling occasion ( 1 day or 1 night) were scored as a ' 1 ' (detection) and occasions with no images or videos of a species were scored as a '0' (non-detection). 


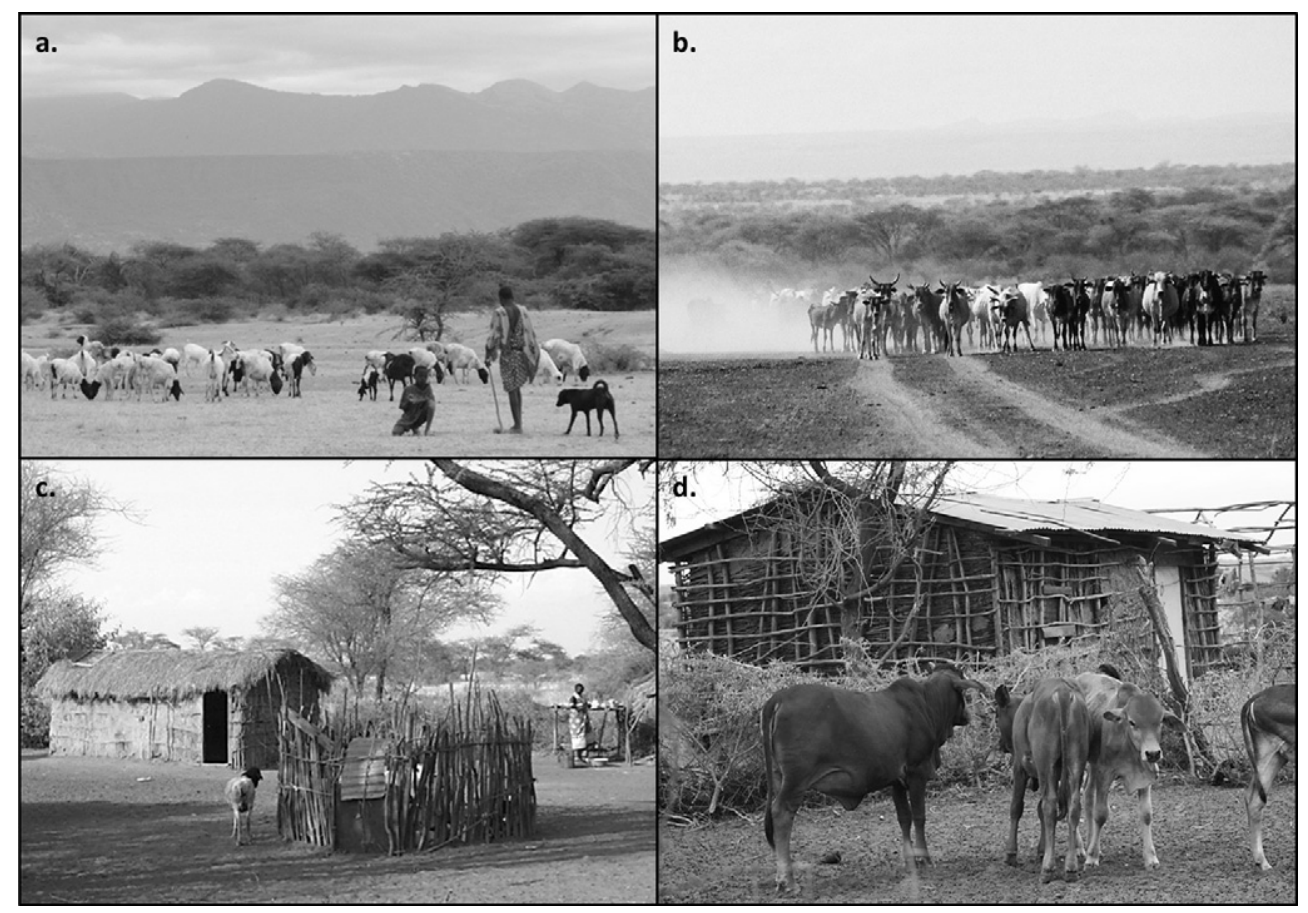

Fig. 2. Human land use in Olkiramatian and Shompole Maasai Group Ranches, Kenya. People move seasonally across the landscape in search of grazing areas for their (a) sheep and goats and (b) cattle. The Buffer area (c) supports active human settlements during the wet season and (d) the Permanent settlement area includes active settlements throughout the year.

For each sampling occasion, we recorded ten anthropogenic, environmental, and procedural variables that we hypothesized might affect carnivore abundance and distribution. Anthropogenic variables included land use (CCA, Buffer, Grazing zone, Permanent settlement), east or west of the river, and distance to nearest active human settlement $(0-10 \mathrm{~km})$, which we mapped every month across the study area. Environmental variables included habitat type (graze [primarily graminoids and forbs], browse [primarily woody vegetation], or graze/browse mix), growing season (green: fresh vegetation, brown: dried vegetation), distance to permanent water (0-8 km), substrate (rock, silty soil, mix), and days into dry season [range: $0-150$ days]. Procedural variables included the cycle (i.e. the primary sampling period (1-7)) and the secondary sampling occasion ( 3 night, 4 day). These procedural variables controlled for the possibility that animals became more or less likely to be detected by cameras over the course of the study or within the 4 days and 3 nights of any one secondary sampling occasion. Breaking the 7 secondary occasions into periods of day and night also allowed us to test for variation among species in diurnal vs nocturnal detection patterns.

\subsubsection{Single species, multi-season occupancy models}

We used multi-season, single-species occupancy models to estimate the probability of occurrence for each species (Fiske et al., 2011; MacKenzie, 2002, 2003; MacKenzie et al., 2006). Multiseason occupancy models provide estimates of dynamic occupancy, consisting of initial occupancy $\left(\hat{\psi}_{1}\right)$ site colonization $(\hat{\gamma})$ and extinction $(\hat{\varepsilon})$ rates (i.e., changes in occupancy between primary sampling periods), and detection probability $(\hat{p})$ (the probability that a species will be detected if it is truly present) (Fiske et al., 2011; MacKenzie, 2003; MacKenzie et al., 2006). We included environmental, anthropogenic and procedural covariates to test their potential influence on each parameter and thus to avoid biased estimates (Fiske et al., 2011; MacKenzie, 2003; MacKenzie et al., 2006) and to identify the factors that most strongly affected local patterns of occupancy.
With 10 covariates that could affect each of four parameters $\left(\hat{\psi}_{1}, \hat{\gamma}, \hat{\varepsilon}\right.$, and $\left.\hat{p}\right)$, the set of candidate models that we might have examined is vast, even without considering interactions between variables or alternative functional forms. Nonetheless, any model that combines a subset of these covariates represents an ecologically reasonable hypothesis, given our current understanding. To greatly reduce this set of potential models, we first used Akaike's Information Criterion (AIC) to select the variable(s) that best described detection probability $(\hat{p})$ for each species, and then held this model of $\hat{p}$ constant for subsequent analyses of factors affecting $\hat{\psi}_{1}, \hat{\gamma}$, and $\hat{\varepsilon}$. This multi-stage approach is reasonable because estimating detection probability was not our primary concern (but is essential to estimate occupancy), and this approach greatly reduced the total number of candidate models for comparison.

In a second stage, we compared a set of 23 models that combined anthropogenic and environmental variables that we hypothesized might affect initial occupancy $\left(\hat{\psi}_{1}\right)$ and seven anthropogenic, environmental, and procedural variables we hypothesized could influence site colonization $(\hat{\gamma})$ and extinction $(\hat{\varepsilon})$ rates. The set of 23 models was constructed to avoid models that included more than one variable related to a given effect (for example, no models included both land use and east/west of the river). This resulted in an a priori set of 161 models (23 combinations of variables potentially influencing $\hat{\psi}_{1} \times 7$ variables potentially influencing $\hat{\gamma}$ and $\hat{\varepsilon}$ ) for each species (see Appendix S1). This model set was not exhaustive, but was aimed to evaluate the influence of various combinations of anthropogenic and environmental variables to test our hypotheses.

We fit dynamic occupancy models using the 'unmarked' package in program R (Fiske et al., 2011; R Development Core Team, 2010), and compared models using AIC scores and AIC weights $(w)$ to determine the best supported models for each species (lowest AIC score and highest $w$ ) (Burnham and Anderson, 2002). We compared the influence of environmental and anthropogenic variables on occupancy, changes in occupancy, and detection probability. We summed AIC weights for all species models containing 
environmental and anthropogenic variables with $w>0.10$, which equated to $\triangle \mathrm{AIC} \leqslant 2$ for all species.

\subsubsection{Temporal partitioning}

We examined fine-scale temporal partitioning among carnivore species by documenting the times when species were detected, using time-stamps that were automatically applied to each image and video when the camera was triggered. Because most African carnivores are highly nocturnal or crepuscular, a day vs night comparison would be relatively uninformative for testing hypotheses of temporal niche partitioning. Consequently, we rearranged our secondary sampling structure for this analysis to partition detections into 8 secondary sampling occasions, consisting of 7 intervals of $2 \mathrm{~h}$ from 6:00 pm-7:59 am to examine dawn, dusk, and nighttime detections, and 1 interval from 8:00 am-5:59 pm to include all daytime detections. In this way, we were able to estimate detection probability for each species at a relevant temporal scale, with differences among species in detection probabilities across time periods providing evidence of temporal niche partitioning. In essence, this approach simply assumes that detection probability increases when a species is more active.

\subsubsection{Spatial partitioning by land use}

Large-bodied carnivores such as lions and spotted hyenas are often the first species to disappear from landscapes affected by humans, and the loss of these apex species can create niche expansion opportunities for subordinate competitors. To examine whether areas heavily utilized by people and livestock were associated with low occupancies for large carnivores and consequent increases in mesocarnivores, we estimated species occupancies across the four land uses alone. To allow direct comparison of effects across species in this analysis, we applied the same generic model to all species, containing land use (with four levels) as the only independent variable for initial occupancy $\left(\hat{\psi}_{1}\right)$, local colonization $(\hat{\gamma})$, and local extinction parameters $(\hat{\varepsilon})$, and each species' respective top detection probability covariate(s) for detection probability $(\hat{p})$. We incorporated each species' 'best' detection probability covariate in an effort to reduce the likelihood that the observation process (variables influencing the ability to detect a species when present) obscured the ecological process of interest (response to land use) (Royle and Dorazio, 2008).

\section{Results}

We recorded 1575 unique detections (per secondary sampling occasion) of 20 carnivorous species. Nineteen species were in the Order Carnivora with diets wholly or largely of meat, but we included the baboon because it includes a substantial proportion of meat in its omnivorous diet, and thus might compete with true Carnivores. Two additional species, the African wild dog and golden jackal, were seen infrequently in the study area, but we recorded no images or videos in our camera surveys. Thus, a minimum of 21 true Carnivores occurred in the study area. The total number of unique detections for each species ranged from 4 (serval) to 436 (bat-eared fox) (Table 1). Models for species with $<27$ unique detections for the species failed to converge, and we did not consider them in our occupancy analyses. Consequently, we obtained sufficient data to assess dynamic occupancy for 12 of the 20 species detected by camera surveys. While we do not discuss the poorly-sampled species further, using species richness as an index, carnivore diversity was locally high. It is notable that 21 species of carnivores, including all 5 of the largest species native to the region (lion, leopard, cheetah, spotted hyena and wild dog), persist in an area that includes no national park and is heavily used by a low-density human population and abundant livestock.

\subsection{Single species, multi-season occupancy}

\subsubsection{General patterns}

The number of variables influencing patterns of occupancy in well-supported models $(w>0.10)$ ranged from 1 to 6 (Table 2). Spotted hyena occupancy was influenced by 6 variables, lions by 5 variables, baboon by 4 variables, wildcat by 3 variables, 6 species (striped hyena, aardwolf, black-backed jackal, civet, genet, bateared fox) by 2 variables, and 2 species (white-tailed mongoose, zorilla) by 1 variable. All environmental variables except growing season (brown/green) appeared in a well-supported model for at least one species. In general, the smaller species were affected by fewer variables.

\subsubsection{Environmental variables}

Summing weights across species, distance to permanent water had the strongest influence on occupancy $\left(\sum w=2.54\right)$, followed by days into dry season $\left(\sum w=1.59\right)$, ground cover $\left(\sum w=1.12\right)$, and habitat $\left(\sum w=0.26\right)$. Lions, spotted hyenas, black-backed jackal, civet, African wildcat, and baboon were more likely to occupy areas near permanent water (Table 2 ). These effects were weak (estimates \pm 1 SE overlapped 0 ) in species with sample sizes of less than 50 detections, including lion, black-backed jackal, and wildcat. Zorilla sample size was also low $(n=27)$, but we found evidence that their occupancy increased in areas far from water.

Lion, spotted hyena, and baboon occupancies declined as the dry season progressed, while aardwolf, civet, wildcat occupancies increased. However, these observed effects were weak (estimates \pm 1 SE overlapped 0) in lion and wildcat (small sample size), aardwolf, and baboon. Lion, spotted hyena, aardwolf, and white-tailed mongoose occupancies were higher in silty substrate areas compared to rock and mixed silt/rock areas. Bat-eared foxes occurred most frequently in habitats dominated by grasses (grazing habitats).

\subsubsection{Anthropogenic variables}

Distance to active human settlements had the strongest anthropogenic influence on occupancies across species ( $\sum w=2.05$ ), followed by land use (CCA, Buffer, Grazing zone, Permanent settlement) ( $\left.\sum w=1.13\right)$, and a simpler land use classification (east/west) $\left(\sum w=0.84\right)$. These three measures are all indices of the likelihood of encounters between carnivores and people, and model selection gave most support to effects due to active settlements, the most fine-scaled measure of human distribution. This suggests that, in this ecosystem, carnivores adjust patterns of occupancy in reaction to human space use in a rather fine-scaled manner, rather than simply avoiding areas associated with high levels of human activity over the long term. Lion, spotted hyena, and baboon (all potential high conflict species) occupancies were high near active human settlements, while striped hyena, black-backed jackal, and wildcat (all low conflict species) occupancies were low near active human settlements. These effects were weak in lions and wildcats (estimates \pm 1 SE overlapped 0 ), likely due to low sample sizes for these species.

Lion and spotted hyena occupancies were highest in the CCA, as was bat-eared fox occupancy. Genet occupancy was lowest in the CCA. Spotted hyena, striped hyena, and baboon occupancies were higher on the west side of the river (CCA, Buffer) than the east side (Grazing zone, Permanent settlement), although this effect was weak in baboon. Genet occupancy was higher on the east side of the river.

\subsubsection{Conclusions}

Summed across species, environmental variables had a greater overall influence on occupancy estimates than anthropogenic effects $\left(\hat{\psi}: \sum w_{\text {env }}>\sum w_{\text {anthro }}\right)$ (Table 2$)$. However, changes in occupancy through time (i.e. across primary sampling periods) were 
Table 1

Total number of unique detections (maximum value ' 1 ' per sampling occasion) from camera surveys. We detected 20 carnivorous species, though baboon does not belong to the order Carnivora.

\begin{tabular}{|c|c|c|}
\hline Carnivore species & $\begin{array}{l}\text { Body } \\
\text { size }\end{array}$ & $\begin{array}{l}\text { \# Unique } \\
\text { detections }\end{array}$ \\
\hline Spotted hyena, Crocuta crocuta ${ }^{\mathrm{a}}$ & Large & 112 \\
\hline Lion, Panthera leo ${ }^{\mathrm{a}}$ & Large & 34 \\
\hline Cheetah, Acinonyx jubatus & Large & 8 \\
\hline Leopard, Panthera pardus & Large & 7 \\
\hline Striped hyena, Hyaena hyaena ${ }^{\mathrm{a}}$ & Medium & 141 \\
\hline Olive baboon $^{\mathrm{a}}$, Papio anubis ${ }^{\mathrm{a}}$ & Medium & 69 \\
\hline Black-backed jackal, Canis mesomelas ${ }^{\mathrm{a}}$ & Medium & 49 \\
\hline Caracal, Felis caracal & Medium & 9 \\
\hline Bat-eared fox, Otocyon megalotis ${ }^{\text {a }}$ & Small & 436 \\
\hline Common genet, Genetta genetta ${ }^{a}$ & Small & 245 \\
\hline Civet, Civettictis civetta ${ }^{\text {a }}$ & Small & 118 \\
\hline White-tailed mongoose, Ichneumia albicauda ${ }^{a}$ & Small & 116 \\
\hline Aardwolf, Proteles cristata ${ }^{\text {a }}$ & Small & 111 \\
\hline Wildcat, Felis sylvestris ${ }^{\text {a }}$ & Small & 33 \\
\hline Zorilla, Ictonyx striatus a & Small & 27 \\
\hline Banded mongoose, Mungos mungo & Small & 19 \\
\hline Egyptian mongoose, Herpestes ichneumon & Small & 15 \\
\hline Honey badger, Mellivora capensis & Small & 14 \\
\hline Marsh mongoose, Atilax paludinosus & Small & 8 \\
\hline Serval cat, Felis serval & Small & 4 \\
\hline
\end{tabular}

${ }^{\mathrm{a}}$ Denotes species analyzed with occupancy models.

influenced more by anthropogenic effects $\left(\hat{\gamma}, \hat{\varepsilon}: \sum w_{e n v}<\sum w_{\text {anthro }}\right)$ In general, this result shows that seasonal changes in human population and livestock populations triggered seasonal changes in carnivore occupancy patterns. For detection probabilities, for all species except lion, $\hat{p}$ was modeled best with environmental variables and procedural variables. Lion detection probability was associated with anthropogenic effects (land use: four levels).

\subsection{Temporal partitioning}

The probability of detecting lions was highest between 10:00 pm and 3:59 am (Fig. 3: intervals 3, 5, 7, 9 h since sunset), peaked between 12:00 am and 1:59 am (interval $7 \mathrm{~h}$ since sunset), and was followed by a secondary peak at dawn from 6:00 to 7:59 am (interval $13 \mathrm{~h}$ since sunset) (Fig. 3 ). This pattern is consistent with high nocturnal hunting, followed by movement into hiding cover around dawn. Spotted hyena detection probability was highest between 12:00 am and 5:59 am (intervals 5, 7, 9, $11 \mathrm{~h}$ since sunset), with a peak from 12:00 am to $1: 59 \mathrm{am}$ (interval $7 \mathrm{~h}$ since sunset) and a secondary peak from $8: 00 \mathrm{pm}$ to 9:59 pm (interval $3 \mathrm{~h}$ since sunset. In general, mesocarnivore detection probabilities, which we interpret as a measure of temporal activity patterns, extended through more time intervals and were less peaked in comparison to lion and spotted hyena (Fig. 3). Aardwolf and bat-eared fox detection probability increased throughout the night and dropped just prior to sunrise. Baboon detection probability followed an expected pattern for a diurnal species, with detection probability above 0 only at sunrise, sunset, and during the daytime hours.

\subsection{Spatial partitioning by land use}

Using the generic model (land use set as the sole variable to describe effects on $\hat{\psi}, \hat{\gamma}, \hat{\varepsilon})$, carnivore occupancies were slightly high-

Table 2

AIC weights $(w)$ for environmental and anthropogenic variables for well-supported models $(w>0.10)$. The direction of the relationship for continuous variables and the condition with the highest occupancy for categorical variables $(\mathrm{s}=$ silty soil, $\mathrm{gr}=\mathrm{Grazing}$ area habitat, $\mathrm{ca}=\mathrm{CCA}, \mathrm{w}=$ west of the river, $\mathrm{e}=$ east of the river) are indicated in parentheses.

\begin{tabular}{|c|c|c|c|c|c|c|c|c|c|c|c|c|c|c|c|c|}
\hline Parameter & Type & Covariate & Lion & Sphy & Sthy & Aard & Jack & Cive & Gene & Bate & Wtmo & Zori & Wcat & Babo & $\sum w_{\text {covariate }}$ & $\sum w_{\text {type }}$ \\
\hline \multirow[t]{7}{*}{$\hat{\psi}_{1}$} & Env & Water & $0.65(-)^{\mathrm{a}}$ & $\begin{array}{l}0.31 \\
(-)\end{array}$ & & & $0.15(-)^{\mathrm{a}}$ & $\begin{array}{l}0.87 \\
(-)\end{array}$ & & & & $0.13(+)$ & $\begin{array}{l}0.31 \\
(-)^{\mathrm{a}}\end{array}$ & $\begin{array}{l}0.12 \\
(-)\end{array}$ & 2.54 & 5.51 \\
\hline & & Dry & $0.53(-)^{\mathrm{a}}$ & $\begin{array}{l}0.31 \\
(-)\end{array}$ & & $\begin{array}{l}0.11 \\
(+)^{\mathrm{a}}\end{array}$ & & $\begin{array}{l}0.21 \\
(+)^{c}\end{array}$ & & & & & $\begin{array}{l}0.31 \\
(+)^{\mathrm{a}}\end{array}$ & $\begin{array}{l}0.12 \\
(-)^{\mathrm{a}}\end{array}$ & 1.59 & \\
\hline & & Ground & $0.14(\mathrm{~s})$ & $\begin{array}{l}0.31 \\
(\mathrm{~s})\end{array}$ & & $\begin{array}{l}0.49 \\
(\mathrm{~s})\end{array}$ & & & & & $0.18(\mathrm{~s})$ & & & & 1.12 & \\
\hline & & Habitat & & & & & & & & $\begin{array}{l}0.26 \\
\text { (gr) }\end{array}$ & & & & & 0.26 & \\
\hline & Anthro & Settlement & $0.14(-)^{\mathrm{b}}$ & $\begin{array}{l}0.31 \\
(-)\end{array}$ & $\begin{array}{l}0.23 \\
(+)\end{array}$ & & $0.56(+)$ & & & & & & $\begin{array}{l}0.31 \\
(+)^{\mathrm{a}}\end{array}$ & $\begin{array}{l}0.50 \\
(-)\end{array}$ & 2.05 & 4.02 \\
\hline & & Land use & 0.53 (ca) & $\begin{array}{l}0.31 \\
\text { (ca) }\end{array}$ & & & & & $\begin{array}{l}0.18 \\
(\mathrm{ca})^{\mathrm{d}}\end{array}$ & $\begin{array}{l}0.11 \\
(\mathrm{ca})\end{array}$ & & & & & 1.13 & \\
\hline & & East/west & & $\begin{array}{l}0.12 \\
(\mathrm{w})\end{array}$ & $\begin{array}{l}0.25 \\
(w)\end{array}$ & & & & $\begin{array}{l}0.34 \\
\text { (e) }\end{array}$ & & & & & $\begin{array}{l}0.13 \\
(w)^{a}\end{array}$ & 0.84 & \\
\hline \multirow[t]{5}{*}{$\hat{\gamma}, \hat{\varepsilon}$} & Env & Dry & & & & & 0.11 & & & & & & & 0.75 & 0.86 & 1.11 \\
\hline & & Habitat & 0.14 & & & & & & & 0.11 & & & & & 0.25 & \\
\hline & Anthro & Land use & & & 0.41 & & & 0.87 & 0.52 & 0.12 & & & & & 1.92 & 3.27 \\
\hline & & Settlement & 0.12 & 0.43 & & 0.49 & & & & & & & 0.31 & & 1.35 & \\
\hline & Constant & $\sim 1$ & $\begin{array}{l}0.39 \text { (water, } \\
\text { dry, use) }\end{array}$ & & & & $\begin{array}{l}0.13 \\
\text { (settlement) }\end{array}$ & & & $\begin{array}{l}0.18 \\
\text { (hab) }\end{array}$ & $\begin{array}{l}0.18 \\
\text { (ground) }\end{array}$ & $\begin{array}{l}0.13 \\
\text { (water) }\end{array}$ & & & 1.01 & 1.01 \\
\hline \multirow[t]{5}{*}{$\hat{p}$} & $\begin{array}{l}\text { Env/ } \\
\text { procedural }\end{array}$ & Day/night & & 0.98 & 0.99 & 1 & 0.97 & 0.81 & 1 & 1 & 0.99 & 1 & 1 & & 9.72 & 15.04 \\
\hline & & Cycle & & & 0.99 & 1 & & & 0.76 & 1 & & & 0.57 & & 4.32 & \\
\hline & & Other & & & & & & & & & & & & 1 & 1 & \\
\hline & Anthro & Land use & 0.51 & & & & & & & & & & & & 0.51 & 0.81 \\
\hline & & East/west & 0.29 & & & & & & & & & & & & 0.29 & \\
\hline
\end{tabular}

Species abbreviations: lion (African lion), sphy (spotted hyena), sthy (striped hyena), aard (aardwolf), jack (black-backed jackal), cive (African civet), gene (common genet), bate (bat-eared fox), wtmo (white-tailed mongoose), zori (zorilla), wcat (African wild cat), babo (olive baboon).

$\sum w_{\text {covariate }}$ is the sum of model weights for well-supported models containing each covariate across species. $\sum w_{t y p e}$ is the sum of the weights for models with covariates classified as environmental or anthropogenic variables.

a Indicates a weak effect (estimate \pm 1 SE overlaps 0 ).

b Indicates a potentially spurious result (see Section 4 ).

c Indicates an increase in occupancy as days into dry season progresses up to $\sim 50$ days and then a decline.

${ }^{\mathrm{d}}$ Indicates land use type where a species exhibited its lowest occupancy. 

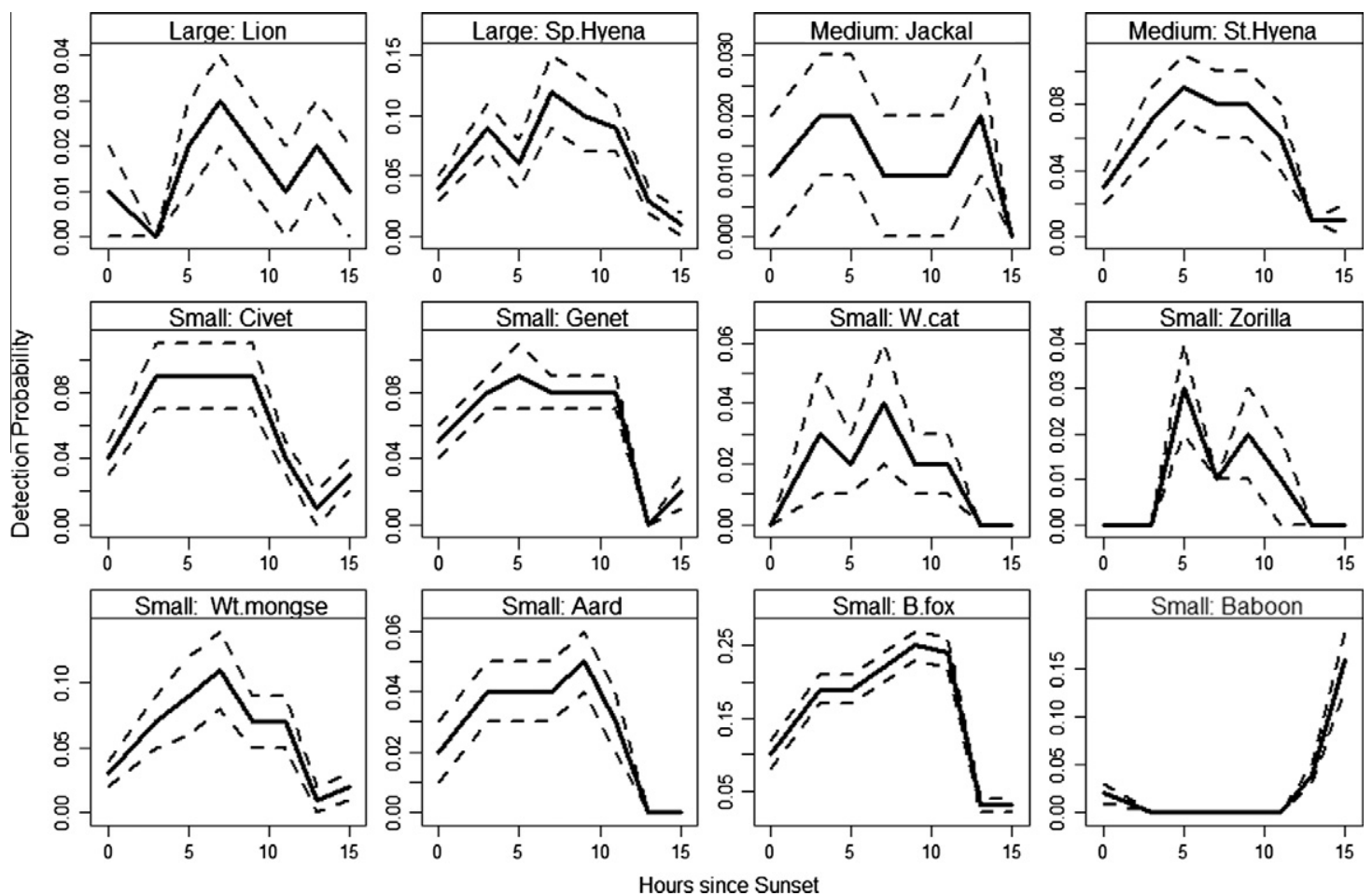

Fig. 3. Estimated detection probability \pm 1 SE for 12 carnivore and omnivore species throughout the night with initial occupancy, colonization, and extinction held constant. Sampling occasions were 72-h nighttime (6:00 pm-7:59 am) intervals and one 10 h daytime interval. Hours since Sunset corresponds to hours since 6 pm. Large dominant carnivores are pictured top left. Mesocarnivores, consisting of medium and small carnivores are pictured at top right and the two lower rows, respectively. Peak detection probabilities for lion and spotted hyena occurred between 12 and 2 am (6-7 h from sunset). Note that the $y$-axes are scaled to the range of detection probabilities for each species in order to show variations in activity patterns across species.

er in the CCA and Buffer (west of river) than the Grazing zone and Permanent settlement land use areas (east of the river) (Fig. 4a). Summed across species, total carnivore occupancy was highest in the CCA $\left(\sum \hat{\psi}_{C C A}=6.78\right)$, followed by the Buffer $\left(\sum \hat{\psi}_{B u f}=6.00\right)$, Permanent settlement $\left(\sum \hat{\psi}_{\text {perm }}=4.43\right)$, and Grazing zone $\left(\sum \hat{\psi}_{\text {Graze }}=3.76\right)$. The large carnivores, including lion, spotted hyena, and medium carnivores, including striped hyena, and blackbacked jackal, occurred at high rates in the CCA (3 of 4 species' occupancies $\sim 1$ ), and declined with increasing human utilization (Buffer $>$ Grazing zone $>$ Permanent settlement). Though spotted hyena, black-backed jackal, and striped hyena occurred at low rates on the east side of the river, lions were rare in the grazing area and absent from the Permanent settlement area (Fig. 4b). In contrast, genet and baboon occupancies were low (and nearly absent) in the CCA, and were relatively high in the Buffer, Grazing zone, and Permanent settlement area. For most mesocarnivores, however, occupancies were highly variable across land use types (Fig. 4b). Contrary to the mesopredator release hypothesis, we did not see a consistent increase in mesocarnivore occupancies as competitively dominant carnivore occupancies declined. This pattern indicated most mesocarnivores did not exhibit a behavioral release and expand their distributions in areas more heavily influenced by people and livestock where dominant carnivore occupancies were low.

\section{Discussion}

\subsection{Species richness}

With 21 detected species of carnivores in our surveyed study area of $228 \mathrm{~km}^{2}$, our results show that it is possible for areas used by people and livestock to support a diverse carnivore community. In this case, coexistence with carnivores was facilitated by the maintenance of traditional pastoralist lifestyles (so that the anthropogenic effects were not constant in most locations), and by the designation of a CCA (so human and livestock activities were minimal for a substantial proportion of the area). While we could not directly estimate densities from the occupancy modeling, densities of carnivores appeared to be relatively high; e.g., individually recognized lions in radio-collared prides had a minimum density of 0.136 lions $>1$ year old $/ \mathrm{km}^{2}$ (Schuette et al., in press) which is comparable to or greater than the density of lions in many national parks (Chardonnet, 2002; Creel and Creel, 1997; Hanby and Bygott, 1995; Mills and Biggs, 1993; Ogutu et al., 2005; Packer et al., 2011; Spong, 2002).

\subsection{Environmental effects and ecological niche partitioning}

Broadly, nearly all of the 12 carnivore species we studied in detail had a unique combination of environmental variables influencing occupancy patterns (except for similarities between lions and spotted hyena, and civet and wildcat) (Table 2). This general pattern is in agreement with the hypothesis that niche partitioning structures the carnivore community and promotes diversity. Nonetheless, several factors had pervasive effects on carnivore distributions, particularly access to water. For six species, occupancies declined at increasing distances from permanent water. Observed positive associations between occupancy and water agree with previous research on lions (Hopcraft et al., 2005; Schuette et al., in press), spotted hyenas (Pettorelli et al., 2010), and civets (Durant et al., 2010; Pettorelli et al., 2010). Dense vegetation within riparian areas is well suited for concealing spotted hyenas and lions as they stalk water-dependent herbivores such as zebra, impala, and Grant's gazelle (Hopcraft et al., 2005; Schaller, 1972). Dense cover may also provide refuge to lions and spotted hyenas exposed to 

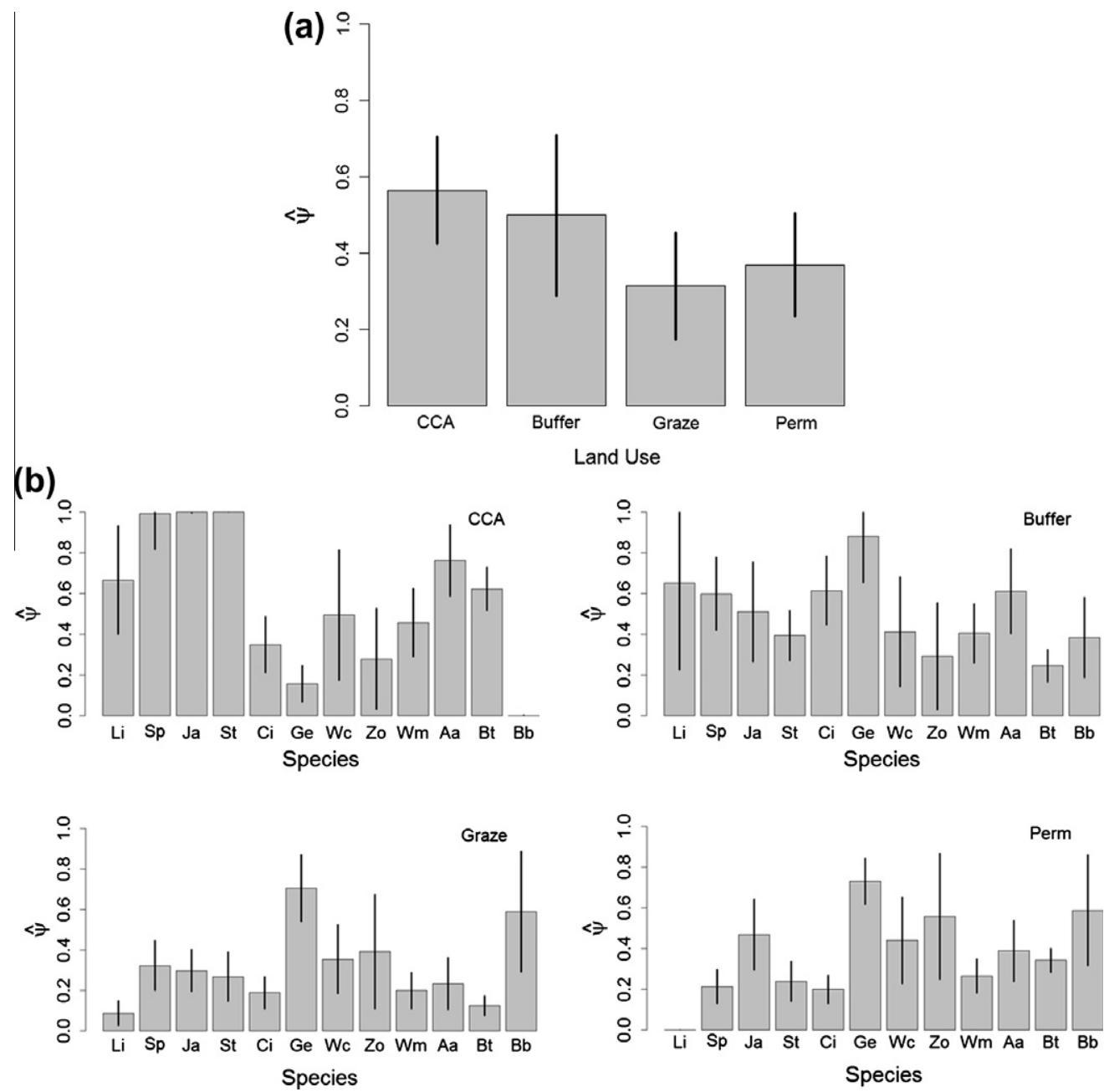

Fig. 4. (a) Mean estimated occupancies ( $\pm 1 \mathrm{SE}$ ) for each land use, averaged across all carnivore species (species richness). (b) Mean estimated occupancies $( \pm 1$ SE) for each species in each land use, using a model with the same covariates for all species ( $\hat{\psi}_{1}$ : land use, $\hat{\gamma}, \hat{\varepsilon}$ : land use). For many species, occupancies were substantially higher in the CCA and Buffer, where human activities were lower, even though species richness was very similar across land use types. However, species evenness was lowest in the CCA, where dominant competitors were most common.

people and livestock (Boydston et al., 2003; Schuette et al., in press).

The dependence of black-backed jackals on permanent water accords with their tendency to follow and scavenge prey items from lions and spotted hyenas. In addition, black-backed jackals have also been observed killing ungulate fawns and small antelope species next to water sources (Krofel, 2008; Schaller, 1972). For baboons, a close connection to riparian areas was expected because they take refuge in the upper reaches of dense stands of trees in riparian areas to sleep as protection from predation by leopards and other large carnivores at night (Cowlishaw, 1997a, 1997b). High wildcat occupancies close to permanent water is a unique observed response for this species, as we are not aware of any other studies showing this pattern. Interestingly, zorilla appeared to avoid permanent water, although it is not clear whether this is related to resource distributions or niche partitioning. In either case, the finding that zorilla occupancy was influenced only by distance to water, negatively, indicates a unique ecology that promotes exploitation of an otherwise unused ecological niche.

Days into dry season influenced occupancy for six of the focal species, but the direction of this effect differed across species. Lion, spotted hyena, and baboon occupancies decreased as the dry season progressed while aardwolf, civet, and wildcat occupancies increased. A declining trend during the dry season supports the notion that lions and spotted hyenas track their ungulate prey into dry season refuges outside the study area such as the Shompole swamp, highlands, and dense woodlands (these areas were not surveyed due to logistical constraints). For baboons, rainfall has been shown to drive changes in temporal activity budgets, including increasing feeding rates and decreasing movement during periods of low rainfall (Bronikowski and Altmann, 1996). As such, the south Rift baboon population may have moved less during the surveyed dry seasons, reducing camera encounter rates relative to the wet seasons. Alternatively, baboons could have moved across larger areas during the dry season to seek out adequate forage, which could also decrease their encounter rates with cameras. In contrast, civets, aardwolves, and African wildcats exhibited higher occupancy rates as the dry season progressed, a pattern indicating higher encounter rates with cameras, likely due to changes in habitat and food availability.

The underlying soil types found across the study area influenced occupancies in a manner that varied among species. Lions, spotted hyenas, aardwolves, and white-tailed mongoose occupancies were higher in areas of silty soil. All sites in the CCA and Buffer were silty, compared to $75 \%$ in the grazing area and $42 \%$ in the Permanent settlement area. Given the high prevalence of lions and spotted hyenas in the CCA and Buffer, we believe that the apparent effect of silty soils is largely an artifact of this land use pattern. 
However, it is also possible that the silty soils in the western portion of our study area near the Rift Valley escarpment are bettersuited for producing higher quality vegetation, which attracts large herbivores and their top predators. It may therefore be fruitful in the future to investigate a potential west to east soil gradient in the south Rift to determine to what extent geological processes have structured plant, herbivore, and carnivore communities.

Interestingly, aardwolves and white-tailed mongooses appeared most frequently in areas of sandy and silty soils, but these two species were not restricted to the CCA and Buffer areas like lions and spotted hyenas were. The difference is likely attributable to the specialized foraging preferences and non-nuisance status of these two smaller carnivores. Aardwolves are hyenids, but have evolved a reduced, peglike dentition and feed almost exclusively on termites from the Trinervitermes and Hodotermes genera, which are found only in softer soils and grasslands (Anderson et al., 1992; Cooper and Skinner, 1979; Kruuk and Sands, 1972; Williams et al., 1997). Similarly, white-tailed mongooses forage primarily on termites and other ground-burrowing invertebrates found in open grassy habitats (Admasu et al., 2004; Waser, 1980).

Finally, beyond human land use attributes, only bat-eared fox occupancy was detectably influenced by habitat type, being highest in open grassland habitats. This result is in agreement with behavioral studies indicating that the highly social bat-eared fox prefers open, short grassland habitats, which promote ease of movement, access to termites and insects, and anti-predator scanning (e.g. 'many eyes' hypothesis) (Koop and Velimirov, 1982; Malcom, 1986; Waser, 1980).

\subsection{Proximity to active human settlements}

Anthropogenic variables appeared in well-supported occupancy models $(w>0.10)$ for eight of 12 species (not aardwolf, civet, white-tailed mongoose, or zorilla). Considering changes in occupancy through time, 10 of 12 species (including aardwolf and civet) were detectably influenced by anthropogenic variables; only white-tailed mongoose and zorilla occupancies were not.

Distance to active human settlements was the most influential anthropogenic variable, appearing in well-supported models for six species, including lion, spotted hyena, striped hyena, blackbacked jackal, wildcat, and baboon. Elevated spotted hyena and baboon occupancy near active human settlements supports the negative, local perception of these species as common livestock predators and frequent raiders on subsistence farms and households, respectively. These patterns are shared across East Africa, where spotted hyenas are known to attack livestock in fenced corrals inside human settlements at night (Kolowski and Holekamp, 2006; Ogada et al., 2003). In addition, anthropogenic food sources are highly attractive to both species (Bronikowski and Altmann, 1996; Kolowski, 2008).

A negative association between lions and distance to active human settlement was evident, but weaker than that of spotted hyena and baboon, likely due to the low number of lion detections in this study $(n=34)$. Estimated lion occupancies were $\sim 1$ from 0 to $5 \mathrm{~km}$ distances, dropping quickly beyond this distance, and the standard errors for all estimates were extremely small $(<0.001)$. In other words, lions were primarily found in close proximity to people (within $5 \mathrm{~km}$ of an occupied settlement). Telemetry data from lions in the area corroborate this result: lions were on average $4779.0 \pm 151.8 \mathrm{~m}$ from occupied settlements when people lived on the east side of the river and $3046.7 \pm 218.1 \mathrm{~m}$ from occupied settlements when people were settled west of the river (Schuette et al., in press). Our occupancy models also indicate that changes in lion occupancy and local extinction, in particular, were negatively associated with distance to active human settlement $\left(\hat{\varepsilon}_{0 \mathrm{~km}}=0.33 \pm 0.23, \hat{\varepsilon}_{10 \mathrm{~km}}=0.19 \pm 0.12\right)$. Though weak, this pattern indicates that if lions were detected at a site during 1 cycle, they were less likely to be detected there again if that site was in close proximity to an active human settlement. Again, lion telemetry data support this pattern. Lions used the Buffer region extensively when people and livestock were settled east of the river (Permanent settlement and Grazing zone areas). However, as people and livestock shifted their settlements to the Buffer area, lions retreated into the CCA (Schuette et al., in press). Thus, a seasonal pattern of shifting human land use corresponds with observed changes in lion occupancy in relation to active human settlements.

Striped hyena, black-backed jackal, and wildcat occupancies were higher at increasing distances to active human settlements. The positive relationship between distance to settlements and jackal occupancy was surprising because black-backed jackals are common livestock predators in other areas and other studies have documented their attraction to anthropogenic food items in human settlements (Gusset et al., 2009; Kaunda and Skinner, 2003). Similarly, striped hyenas are rarely involved in conflicts locally, but they are capable of attacking livestock calves, sheep and goats. Despite this, our data suggest striped hyenas avoided active human settlements and we are not aware of any local conflicts with striped hyenas. Finally, the African wildcat also avoided active human settlements, a behavioral pattern that could reduce the chance of hybridization with domestic cats, which is the biggest threat to this small carnivore (Driscoll and Nowell, 2010).

Small sample sizes for several species (lion, wildcat, zorilla, black-backed jackal) could lead to overfitting of complex models (Stockwell and Peterson, 2002). In our occupancy models, small sample sizes could have led to spurious results in which a noninfluential variable could appear to be important. For this reason, we suggest caution in interpreting results from species with low sample sizes (e.g. $n<50$ ), particularly in those instances where the standard errors associated with the occupancy point estimates overlapped 0 (e.g. lion, wildcat, zorilla, black-backed jackal). We chose to include these results because they may be important to conservation and management. Future research should investigate the extent to which these variables may affect carnivore ecology and conservation.

Additionally, large carnivores such as lion, spotted hyena, and striped hyena, are capable of visiting multiple sub-locations during a sampling occasion (12-h interval), which could lead to problems with spatial autocorrelation. Though our analytical methods did not explicitly test for spatial autocorrelation, we examined this potential issue in a conservative, post hoc manner. By visually inspecting the data, we counted the number of sampling occasions in which adjacent sub-locations were visited by the same species (e.g. lion, spotted hyena, striped hyena) during the same sampling occasion. This occurred two times in lions, six times in spotted hyenas, and eight times in striped hyenas. We removed all duplicate detections at adjacent sub-locations and then re-ran the occupancy models with the reduced dataset. Removing these duplicate detections resulted in a sample size of 32 (compared to 34) for lion, 105 (compared to 112) for spotted hyena, and 134 (compared to 141) for striped hyena. Through this post hoc assessment, we found that the variables that influenced $(w>0.10)$ lion, spotted hyena, and striped hyena occupancy patterns did not change. Though we found little evidence of spatial autocorrelation in our analysis, we consider this an issue that should be considered more directly in future occupancy analyses.

\subsection{Temporal partitioning}

For subordinate carnivore species, temporal niche partitioning is often an evolutionary advantageous strategy for avoiding dominant competitors that can injure or kill them, or steal their food (Fedriani et al., 2000; Hayward and Slotow, 2009; Linnell and 
Strand, 2000; Mills and Biggs, 1993; Neale and Sacks, 2001). In this study, we used a novel approach to assess temporal partitioning by comparing each species' estimated detection probability during nighttime hours. This analysis indicated that the two locally dominant competitors (lion, spotted hyena) were most active during the middle of the night (Fig. 3), but that peak lion activity was possibly shorter in duration and centered around midnight more so than in spotted hyena, a pattern also observed by Mills and Biggs (1993). In contrast, several small and medium-sized carnivores, including black-backed jackal, striped hyena, civet, wildcat, and genet, exhibited notably broader temporal activity patterns or a pattern that peaked just before and after midnight (e.g. zorilla). These patterns agree with an expected pattern of temporal displacement wherein top competitors rule their preferred time periods, temporally displacing subordinate species (Fedriani et al., 2000; Hayward and Slotow, 2009; Linnell and Strand, 2000; Mills and Biggs, 1993; Neale and Sacks, 2001) (Fig. 5).

Though observed temporal patterns from detection probability were informative, we acknowledge that our approach relies on the untested, but reasonable, assumption that detection probability increases when animals are more active. Because our method is new, we compared our results with a strategy developed by Ridout and Linkie (2009), which calculates a measure of temporal overlap, termed coefficient of overlap, among interacting species. Coefficients of overlap are calculated nonparametrically using kernel density estimates, and range from 0 (no temporal overlap) to 1 (perfect temporal overlap) (Linkie and Ridout, 2011; Ridout and Linkie, 2009). With this method, we calculated the coefficient of overlap and associated precision through bootstrapping among lion, spotted hyena, and 10 smaller species. We found that lions, on average (excluding baboon because of their diurnal activity), exhibited a coefficient of overlap of 0.76 (95\% CI: 0.56-0.81), which was slightly lower than the average coefficient of overlap for spotted hyenas, 0.87 (95 C\% Cl: 0.73-0.90) (Fig. 6) [Pairwise plots between lions and spotted hyenas with each of the 10 smaller carnivores are available as Appendix S2]. In general, the model proposed by Ridout and Linkie (2009) supports results from our detection probability analysis of temporal partitioning, indicating that smaller carnivores overlap with dominant carnivores, but not completely, and that temporal partitioning among species may promote coexistence.

Though we attribute temporal partitioning largely to competitive interactions, other conditions, such as temperature, might also explain observed temporal patterns (Hayward and Slotow, 2009; Mills and Biggs, 1993). Using temperature records from $>40,000$ camera images, we estimated an average temperature of $34.5 \pm$

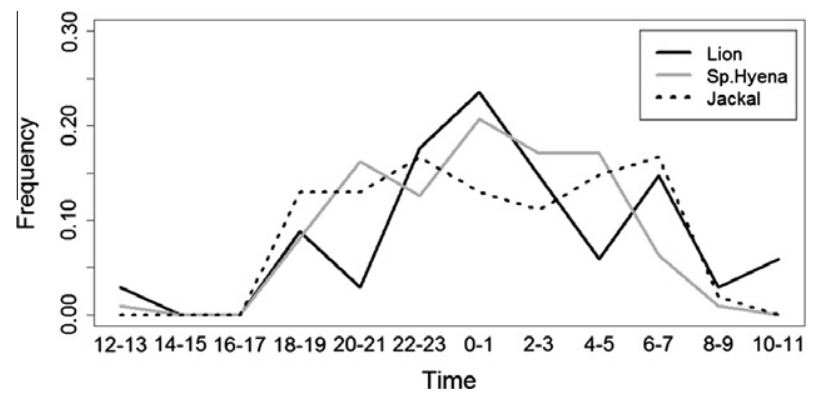

Fig. 5. Diurnal activity patterns for a top carnivore (lion), a close competitor (spotted hyena), and a subordinate competitor (black-backed jackal). Frequency represents the proportion of detections for each species that fell within each 2-h time interval. We present time intervals on a 24-h cycle, from $12 \mathrm{pm}$ at left to $11 \mathrm{am}$ at right. Peak lion activity occurred around midnight and competitor activity was spread more broadly throughout the night.

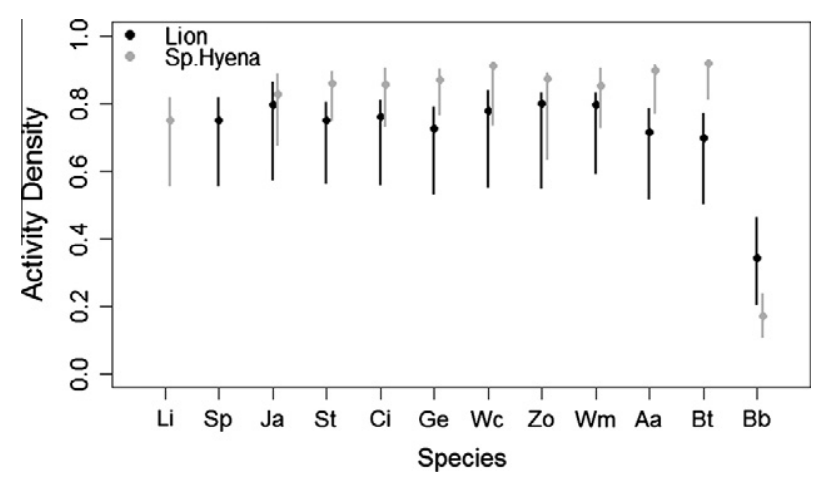

Fig. 6. Estimates of activity densities (i.e. coefficients of overlap) and bootstrapped 95\% CIs based on a kernel density estimation strategy (Ridout and Linkie, 2009) among 2 dominant competitors (lion and spotted hyena) and 10 sympatric carnivore species. Activity densities scale from 0 (no temporal overlap) to 1 (perfect temporal overlap). Species codes are defined in Table 1.

$0.10^{\circ} \mathrm{C}$ at sunset that steadily declined throughout the night to a low of $24.2 \pm 0.09^{\circ} \mathrm{C}$ (Fig. 7) at sunrise. Only bat-eared fox, aardwolves, and white-tailed mongoose activity corresponded with temperature (which, interestingly, all feed on termites). Given this, we suspect the activity patterns for most of the small and mediumsized carnivores represented a balance between those behaviors devoted to foraging and reproduction (and care of young) and responses to restrictions imposed by competitors.

Human-modified landscapes may also impose restrictions on activity budgets in mesocarnivores. In the south Rift, people and livestock are active from just before sunrise to just after sunset, time periods when many smaller carnivores are still active in landscapes where humans are absent (Waser, 1980). Thus, the temporal activity budgets of mesocarnivores in the south Rift likely may reflect additional behavioral shifts that serve to avoid potential dangerous encounters with people, livestock, and guard dogs (which typically accompany Maasai livestock herds).

\subsection{Human land use effects: implications for species richness, evenness, and mesopredator release}

We found that the CCA and Buffer land use types supported higher overall carnivore occupancies than the Grazing zone and Permanent settlement land use types, which are used more regularly by people and livestock (Fig. 3a). High lion and spotted hyena occupancies in the CCA, which declined as human utilization increased, indicates these two potential conflict species prefer areas

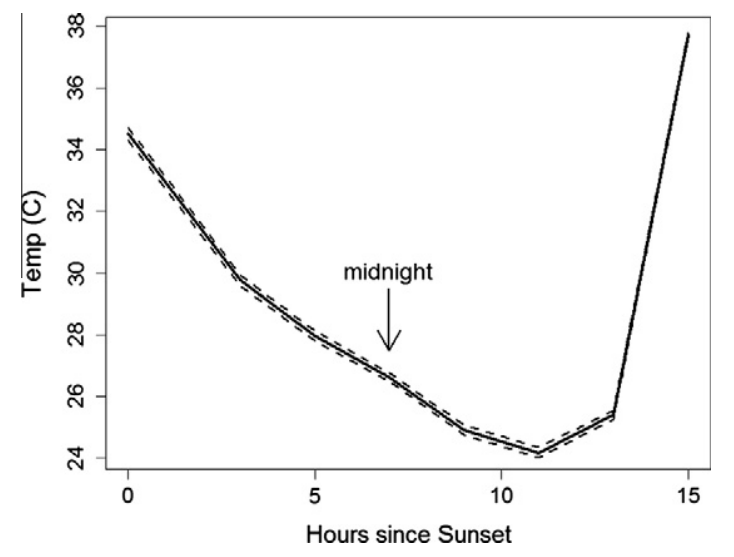

Fig. 7. Mean ambient temperature and $95 \% \mathrm{Cl}$ from time stamps on camera images. Time 0 corresponds to $6 \mathrm{pm}$ (sunset), $12 \mathrm{~h}$ since sunset corresponds to $6 \mathrm{am}$ (sunrise), and $15 \mathrm{~h}$ corresponds to the daytime hours (collectively) of 8:00 am through 5:59 pm. 
used less by people and livestock. The CCA appears to provide sufficient habitat and prey to attract and sustain regular use of the CCA by lions and spotted hyenas. High lion and spotted hyena occupancies west of the river (CCA, Buffer) and low occupancies east of the river could have allowed mesocarnivores to increase in abundance or expand their distributions (i.e. mesopredator release). Though we do not have data on the abundance of mesocarnivores, we found little evidence of mesocarnivores expanding their range (i.e. increased occupancies) into areas less-used by apex carnivores. For most small and medium-sized carnivores (8 of 10), occupancies remained similar or decreased moving from the CCA in the west to the Permanent settlement area in the east. Though we did not see consistent increases in mesocarnivore occupancies in the near absence of apex predators, the potential for such an effect remains as most mesocarnivores persisted in areas of active human land use across the landscape.

High carnivore diversity across this mixed-use landscape and variable patterns of species occupancy relative to human land use provoked us to consider species evenness as an additional measure of carnivore dynamics. We developed a coarse measure of species evenness that incorporates species occupancies across the four land uses:

$E=\sum_{i=1}^{n}\left|\overline{\hat{\psi}}_{L_{n}}-\hat{\psi}_{L_{s p_{i}}}\right|$

Eq. (1) calculates the cumulative sum of the absolute values for the difference between mean occupancy for all focal species $(n)$ in a land use type $(L)$ and species $i$ in that land use type. For example, an $E$-value 0 would indicate perfect evenness, i.e., that all species occupancies were the same in that land use.

Comparing evenness across land use types, the Buffer, Grazing, and Permanent settlement land use types showed similar species evenness ( $E=1.74,1.59,1.94$, respectively), while the CCA was much more uneven $(E=3.31)$. As a result, though the CCA has high species richness, it is also the most uneven in terms of species occupancies. However, this pattern is largely due to high occupancies in the larger-bodied carnivores relative to the other species, and occupancies for most mesocarnivores (except genet and baboon) in the CCA were high relative to rates in other land uses. This indicates that the well-protected CCA is vital for sustaining the observed carnivore diversity in the surrounding mixed-use landscape.

\section{Acknowledgements}

We thank the Kenya Ministry of Science and Technology and the Kenya Wildlife Service for permission to conduct our research. We thank J. Kamanga, S. Russell, and D. Western for their coordination efforts, and M. Kapoli, P. Moikinyo, L. Mpukere, P. Oltubulai, A. Kuseyo, and J. Njonjo for their assistance in the field. This research was funded by the National Science Foundation, the Cincinnati Zoo, and Panthera Corporation.

\section{Appendix A. Supplementary material}

Supplementary data associated with this article can be found, in the online version, at http://dx.doi.org/10.1016/j.biocon.2012.08. 008 .

\section{References}

Admasu, E., Thirgood, S.J., Bekele, A., Laurenson, M.K., 2004. Spatial ecology of white-tailed mongoose in farmland in the Ethiopian Highlands. Afr. J. Ecol. 42, 153-159.

Anderson, M.D., Richardson, P.R.K., Woodall, P.F., 1992. Functional analysis of the feeding apparatus and digestive tract anatomy of the aardwolf Proteles cristatus. J. Zool. 228, 423-434.
Boydston, E.E., Kapheim, K.M., Watts, H.E., Szykman, M., Holekamp, K.E., 2003. Altered behaviour in spotted hyenas associated with increased human activity. Anim. Conserv. 6, 207-219.

Bronikowski, A.M., Altmann, J., 1996. Foraging in a variable environment: weather patterns and the behavioral ecology of baboons. Behav. Ecol. Sociobiol. 39, 1125.

Burnham, K.P., Anderson, D.R., 2002. Model Selection and Multimodel Inference: A Practical Information-Theoretic Approach. Springer.

Caro, T.M., Stoner, C., 2003. The potential for interspecific competition among African carnivores. Biol. Conserv. 110, 67-75.

Chardonnet, P., 2002. Conservation of the African Lion: Contribution to a Status Survey. International Foundation for the Conservation of Wildlife, France \& Conservation Force, USA.

Cooley, H.S., Wielgus, R.B., Koehler, G.M., Robinson, H.S., Maletzke, B.T., 2009. Does hunting regulate cougar populations? A test of the compensatory mortality hypothesis. Ecology 90, 2913-2921.

Cooper, R., Skinner, J., 1979. Importance of termites in the diet of the aardwolf Proteles cristatus in South Africa. S. Afr. J. Zool. 14, 5-8.

Cowlishaw, G., 1997a. Trade-offs between foraging and predation risk determine habitat use in a desert baboon population. Anim. Behav. 53, 667-686.

Cowlishaw, G., 1997b. Refuge use and predation risk in a desert baboon population. Anim. Behav. 54, 241-253.

Creel, S., Creel, N.M., 1995. Communal hunting and pack size in African wild dogs, Lycaon pictus. Anim. Behav. 50, 1325-1339.

Creel, S., Creel, N.M., 1996. Limitation of African wild dogs by competition with larger carnivores. Conserv. Biol. 10, 526-538.

Creel, S., Creel, N.M., 1997. Lion density and population structure in the Selous Game Reserve: evaluation of hunting quotas and offtake. Afr. J. Ecol. 35, 83-93.

Creel, S., Creel, N.M., 2002. The African Wild Dog: Behavior, Ecology and Conservation. Princeton University Press, Princeton, New Jersey.

Creel, S., Rotella, J.J., 2010. Meta-analysis of relationships between human offtake, total mortality and population dynamics of gray wolves (Canis lupus). PLoS ONE 5, e12918.

Creel, S., Spong, G., Creel, N.M., 2001. Interspecific competition and the population biology of extinction-prone carnivores. In: Gittleman, J.L., Funk, S.M., Macdonald, D., Wayne, R.K. (Eds.), Carnivore Conservation. Cambridge University Press, Cambridge, pp. 35-60.

Crooks, K.R., Soulé, M.E., 1999. Mesopredator release and avifaunal extinctions in a fragmented system. Nature 400, 563-566.

Dalerum, F., Cameron, E., Kunkel, K., Somers, M., 2009. Diversity and depletions in continental carnivore guilds: implications for prioritizing global carnivore conservation. Biol. Lett. 5, 35-38.

Dayan, T., Simberloff, D., Tchernov, E., Yom-tov, Y., 1992. Canine carnassials: character displacement in the wolves, jackals and foxes of Israel. Biol. J. Linn. Soc. 45, 315-331

Driscoll, C., Nowell, K., 2010. IUCN Red List of Threatened Species: Felis silvestris. IUCN 2011. <iucnredlist.org>.

Durant, S.M., 1998. Competition refuges and coexistence: an example from Serengeti carnivores. J. Anim. Ecol. 67, 370-386.

Durant, S.M., Craft, M.E., Foley, C., Hampson, K., Lobora, A.L., Msuha, M., Eblate, E., Bukombe, J., Mchetto, J., Pettorelli, N., 2010. Does size matter? An investigation of habitat use across a carnivore assemblage in the Serengeti, Tanzania. J. Anim. Ecol. 79, 1012-1022.

Estes, R.D., Goddard, J., 1967. Prey selection and hunting behavior of the African wild dog. J. Wildl. Manage. 31, 52-70.

Fanshawe, J.H., Fitzgibbon, C.D., 1993. Factors influencing the hunting success of an African wild dog pack. Anim. Behav. 45, 479-490.

Fedriani, J.M., Fuller, T.K., Sauvajot, R.M., York, E.C., 2000. Competition and intraguild predation among three sympatric carnivores. Oecologia 125, 258-270.

Fiske, I.J., Chandler, R.B., 2011. Unmarked: an R package for fitting hierarchical models of wildlife occurrence and abundance. J. Stat. Softw. 43, 1-23.

Fiske, I.J., Chandler, R.B., Royle, J.A., 2011. Unmarked: Models for Data from Unmarked Animals. <http://CRAN.R-project.org/package=unmarked>.

Gardner, T.A., Caro, T.M., Fitzherbert, E.B., Banda, T., Lalbhai, P., 2007. Conservation value of multiple-use areas in east Africa. Conserv. Biol. 21, 1516-1525.

Gorman, M.L., Mills, M.G.L., Raath, J.P., Speakman, J.R., 1998. High hunting costs make African wild dogs vulnerable to kleptoparasitism by hyaenas. Nature 391, 479-481.

Gusset, M., Swarner, M.j., Mponwane, L., Keletile, K., McNutt, J.w., 2009. Humanwildlife conflict in Northern Botswana: livestock predation by endangered African wild dog Lycaon pictus and other carnivores. Oryx 43, 67-72.

Hanby, J.P., Bygott, J.D., 1995. Population changes in lions and other predators. In: Sinclair, A.R.E., Norton-Griffiths, M. (Eds.), Serengeti: Dynamics of an Ecosystem. University of Chicago Press, pp. 249.

Hardin, G., 1960. The competitive exclusion principle. Science 131, 1292-1297.

Hayward, M.W., Slotow, R., 2009. Temporal partitioning of activity in large African carnivores: tests of multiple hypotheses. S. Afr. J. Wildlife Res. 39, 109-125.

Hazzah, L., Borgerhoff Mulder, M., Frank, L.G., 2009. Lions and warriors: social factors underlying declining African lion populations and the effect of incentive-based management in Kenya. Biol. Conserv. 142, 2428-2437.

Homewood, K., Kristjanson, P., Trench, P.C., 2009. Changing Land Use, Livelihoods, and Wildlife Conservation in Maasailand. Staying Maasai? Livelihoods, Conservation and Development in East African Rangelands. Springer Science + Business Media, New York, pp. 1-42.

Hopcraft, G., Sinclair, A.R.E., Packer, C., 2005. Planning for success: Serengeti lions seek prey accessibility rather than abundance. J. Anim. Ecol. 74, 559-566. 
Karanth, K.U., Sunquist, M.E., 1995. Prey selection by tiger, leopard and dhole in tropical forests. J. Anim. Ecol., 439-450.

Kaunda, S.K.K., Skinner, J.D., 2003. Black-backed jackal diet at Mokolodi Nature Reserve, Botswana. Afr. J. Ecol. 41, 39-46.

Kenya's National Large Carnivore Task Force, 2008. Conservation and Management Strategy for Lions and Spotted Hyenas in Kenya, 2009-2014. Kenya Wildlife Service, Nairobi, Kenya, p. 52.

Kissui, B.M., 2008. Livestock predation by lions, leopards, spotted hyenas, and their vulnerability to retaliatory killings in the Maasai steppe, Tanzania. Anim. Conserv. 11, 422-432.

Kitchen, A.M., Gese, E.M., Schauster, E.R., 1999. Resource partitioning between coyotes and swift foxes: space, time, and diet. Can. J. Zool. 77, 1645-1656.

Kolowski, J.M., 2008. Effects of an open refuse pit on space use patterns of spotted hyenas. Afr. J. Ecol. 46, 341-349.

Kolowski, J.M., Holekamp, K.E., 2006. Spatial, temporal, and physical characteristics of livestock depredations by large carnivores along a Kenyan reserve border. Biol. Conserv. 128, 529-541.

Koop, K., Velimirov, B., 1982. Field observations on activity and feeding of bat-eared foxes (Otocyon megalotis) at Nxai Pan, Botswana. Afr. J. Ecol. 20, 23-27.

Krofel, M., 2008. Opportunistic hunting behaviour of black-backed jackals in Namibia. Afr. J. Ecol. 46, 220-222.

Kruuk, H., Sands, W., 1972. The aardwolf (Proteles cristatm Sparrman) 1783 as predator of termites. Afr. J. Ecol. 10, 211-227.

Linkie, M., Ridout, M.S., 2011. Assessing tiger-prey interactions in Sumatran rainforests. J. Zool. 284, 224-229.

Linnell, J.D.C., Strand, O., 2000. Interference interactions, co-existence and conservation of mammalian carnivores. Divers. Distrib. 6, 169-176.

MacKenzie, D.I., 2002. Estimating site occupancy rates when detection probabilities are less than one. Ecology 83, 2248-2255.

MacKenzie, D.I., 2003. Estimating site occupancy, colonization, and local extinction when a species is detected imperfectly. Ecology 84, 2200-2207.

MacKenzie, D.I., Nichols, J.D., Royle, J.A., Pollock, K.H., Bailey, L.L., Hines, J.E., 2006 Occupancy Estimation and Modeling: Inferring Patterns and Dynamics of Species Occurrence. Academic Press, Burlington, MA.

Malcolm, J.R., Marten, K., 1982. Natural selection and the communal rearing of pups in African wild dogs (Lycaon pictus). Behav. Ecol. Sociobiol. 10, 1-13.

Malcom, J.R., 1986. Socio-ecology of Bat-eared foxes (Otocyon megalotis). J. Zool. 208, 457-469.

Martinoli, A., Preatoni, D., Galanti, V., Codipietro, P., Kilewo, M., Fernandes, C.A.R. Wauters, L.A., Tosi, G., 2006. Species richness and habitat use of small carnivores in the Arusha National Park (Tanzania). Biodivers. Conserv. 15, 1729-1744.

Mills, M.G.L., Biggs, H.C., 1993. Prey Apportionment and Related Ecologica Relationships between Large Carnivores in Kruger National Park. Symposia of the Zoological Society of London, pp. 253-268.

Mills, M.G.L., Nel, J.A.J., Bothma, J.P., 1984. Notes on some smaller carnivores from the Kalahari Gemsbok National Park. Koedoe - Afr. Protect. Area Conserv. Sci. 27, 221-227.

Neale, J.C.C., Sacks, B.N., 2001. Food habits and space use of gray foxes in relation to sympatric coyotes and bobcats. Can. J. Zool. 79, 1794-1800.

Noss, R.F., Quigley, H.B., Hornocker, M.G., Merrill, T., Paquet, P.C., 1996. Conservation biology and carnivore conservation in the Rocky Mountains. Conserv. Biol. 10, 949-963.

Nudds, T.D., 1978. Convergence of group size strategies by mammalian social carnivores. Am. Nat. 112, 957-960.

Ogada, M.O., Woodroffe, R., Oguge, N.O., Frank, L.G., 2003. Limiting depredation by African carnivores: the role of livestock husbandry. Conserv. Biol. 17, 1521-1530.

Ogutu, J.O., Bhola, N., Reid, R., 2005. The effects of pastoralism and protection on the density and distribution of carnivores and their prey in the Mara ecosystem of Kenya. J. Zool. 265, 281-293.

Owen-Smith, N., Mills, M.G.L., 2008. Predator-prey size relationships in an African large-mammal food web. J. Anim. Ecol. 77, 173-183.

Packer, C., Brink, H., Kissui, B.M., Maliti, H., Kushnir, H., Caro, T.M., 2011. Effects of trophy hunting on lion and leopard populations in Tanzania. Conserv. Biol. 25, 142-153.
Packer, C., Kosmala, M., Cooley, H.S., Brink, H., Pintea, L., Garshelis, D., Purchase, G., Strauss, M., Swanson, A., Balme, G.A., Hunter, L., Nowell, K., 2009. Sport hunting predator control and conservation of large carnivores. PLoS ONE 4.

Palomares, F., Caro, T.M., 1999. Interspecific killing among mammalian carnivores. Am. Nat. 153, 492-508.

Pettorelli, N., Lobora, A.L., Msuha, M.J., Foley, C., Durant, S.M., 2010. Carnivore biodiversity in Tanzania: revealing the distribution patterns of secretive mammals using camera traps. Anim. Conserv. 13, 131-139.

Pfennig, K.S., Pfennig, D.W., 2005. Character displacement as the "best of a bad situation": fitness trade-offs resulting from selection to minimize resource and mate competition. Evolution 59, 2200-2208.

Polis, G.A., Myers, C.A., Holt, R.D., 1989. The ecology and evolution of intraguild predation: potential competitors that eat each other. Annu. Rev. Ecol. Syst. 20, 297-330.

R Development Core Team, 2010. R: A Language and Environment for Statistical Computing. R Foundation for Statistical Computing, Vienna, Austria. <http:// www.R-project.org>.

Ray, J.C., Hunter, Luke., Zigouris, J., 2005. Setting Conservation and Research Priorities for Larger African Carnivores. Wildlife Conservation Society, New York.

Ridout, M., Linkie, M., 2009. Estimating overlap of daily activity patterns from camera trap data. J. Agric. Biol. Environ. Stat. 14, 322-337.

Ritchie, E.G., Johnson, C.N., 2009. Predator interactions, mesopredator release and biodiversity conservation. Ecol. Lett. 12, 982-998.

Robinson, H.S., Wielgus, R.B., Cooley, H.S., Cooley, S.W., 2008. Sink populations in carnivore management: cougar demography and immigration in a hunted population. Ecol. Appl.: Publ. Ecol. Soc. Am. 18, 1028-1037.

Royle, J.A., Dorazio, R.M., 2008. Hierarchical Modeling and Inference in Ecology. Academic Press, London.

Schaller, G.B., 1972. The Serengeti Lion: A Study of Predator-Prey Relations. University of Chicago Press.

Schipper, J., Hoffmann, M., Duckworth, J., CONROY, J., 2008. The 2008 IUCN red listings of the world's small carnivores. Small Carnivore Conserv. 39 29-34.

Schuette, P., 2012. Factors Affecting the Distribution and Abundance of Carnivores and Their Ungulate Prey across a Communally Owned Rangeland in Kenya. Ph.D. Dissertation, Montana State University, Bozeman, Montana.

Schuette, P., Creel, S., Christianson, D., in press. Coexistence of African lions, livestock, and people with variable land use and seasonal movements. Biol. Conserv.

Sinclair, A.R.E., Mduma, S.A.R., Brashares, J.S., 2003. Patterns of predation in a diverse predator-prey system. Nature $425,288-290$.

Spong, Goran, 2002. Space use in lions, Panthera leo, in the Selous Game Reserve: social and ecological factors. Behav. Ecol. Sociobiol. 52, 303-307.

Stockwell, D.R., Peterson, A.T., 2002. Effects of sample size on accuracy of species distribution models. Ecol. Model. 148, 1-13.

Virani, M.Z., Kendall, C., Njoroge, P., Thomsett, S., 2011. Major declines in the abundance of vultures and other scavenging raptors in and around the Masai Mara ecosystem, Kenya. Biol. Conserv. 144, 746-752.

Warinda, E., 2001. A Socioeconomic Survey and Analysis of Land Use Options in Shompole and Olkiramatian Group Ranches-Magadi Division. African Conservation Centre, Nairobi, Kenya.

Waser, P.M., 1980. Small nocturnal carnivores: ecological studies in the Serengeti. Afr. J. Ecol. 18, 167-185.

Waser, P.M., 1981. Sociality or territorial defense? The influence of resource renewal. Behav. Ecol. Sociobiol. 8, 231-237.

Williams, J.B., Anderson, M.D., Richardson, P.R.K., 1997. Seasonal differences in field metabolism, water requirements, and foraging behavior of free-living aardwolves. Ecology 78, 2588-2602.

Woodroffe, R. 2000. Predators and people: using human densities to interpret declines of large carnivores 3, 165-173.

Woodroffe, R., Ginsberg, J.R., 1998. Edge effects and the extinction of populations inside protected areas. Science 280, 2126-2128. 